\title{
Curbing Malnutrition and Micronutrient Deficiencies in India... Food Based Strategies at the Centre of a Holistic Approach
}

\author{
Ravi Prakash Upadhyay \\ Resident, Centre for Community Medicine, All India Institute of Medical Sciences, New Delhi, India
}

\section{ABSTRACT}

India has the largest number of undernourished people in the world. Malnutrition is a major problem with nearly $55 \%$ of the pre-school children and one-third of women in the age group 15-49 years being underweight. The problem of malnutrition is causing an economic pullback as India tends to lose 3-4\% of the Gross Domestic Product (GDP) in terms of loss of productivity. This glaring problem of malnutrition and micronutrient deficiencies is multi-factorial. Important causes include lack of improvement in agricultural productivity owing to inadequate resources, lack of education and inadequate job opportunities. Increased informal workforce due to rural-urban migration along with unplanned growth of slums is one of the key issues in the urban set-up. Other factors catalyzing the problem include overpopulation, gender inequality, inadequate distribution of food through public distribution mechanisms and lack of coherent nutrition policies. The government policies should focus on growth in agriculture and on improving the food storing facilities. An accurate targeting of "in need" population, so that they get food at substantially low price along with introduction of holistic employment schemes is required. Nutrition based programmes should have in-built system of evaluation based on key nutritional indicators. Social determinants of health such as water, sanitation and women empowerment also have to be addressed to achieve long term gains in the health of the community. Community awareness and mass movement is required to ensure that demographic dividend might not turn into demographic nightmare. Keeping in view that nutrition is not a 'stand alone' subject, a multisectoral approach is needed.

Key words: Malnutrition, micronutrient deficiency, prevention, India

\section{INTRODUCTION}

Malnutrition is a broad term which refers to both under nutrition and over-nutrition. Individuals are malnourished, or suffer from under-nutrition, if their diet does not provide them with adequate calories and protein for maintenance and growth, or they cannot fully utilize the food they eat due to illness. People are also malnourished, or suffer from over-nutrition, if they consume too many calories. The current manuscript will focus on the under-nutrition aspect of malnutrition rather than over-nutrition.

Address for correspondence: Dr. Ravi Prakash Upadhyay

Resident, Centre for Community Medicine

All India Institute of Medical Sciences

New Delhi, India, Fax: 0129-2211227

Phone Number: +91-9911645513

E-mail: ravi.p.upadhyay@gmail.com

DOI: $10.5530 /$ ijmedph.4.2011.6
The problem of chronic hunger and malnutrition seems to prevail on a large scale in India and other developing countries. India has the largest number of undernourished people in the world, 212 million - only marginally below the 215 million estimated for 199092. ${ }^{[1]}$ The Global Hunger Index (GHI) for India in the year 2010 was 24.1 which placed it in the "alarming category" (ranked 67, way below neighbouring countries like China and Pakistan). ${ }^{[2]}$ This index was 31.7 in year 1990 which declined to 23.9 in 2009. ${ }^{[3]}$ According to the NFHS-2 and NFHS-3 reports, $36.2 \%$ and $33 \%$ of the women (aged 15-49 years) respectively had their body mass index (BMI) below normal (a negligible change in the last seven years) ${ }^{[4,5]}$ The findings are dismal in case of children with $45.9 \%$ of the children below the age of 3 years being underweight or malnourished, according to the NFHS-3 report. ${ }^{[5]}$ Surprisingly, India is one of the few countries which has experimented with a broad spectrum of food based programmes like "Entitlement feeding programmes" (ICDS, Mid-day meal programme), "Food 
Subsidy Programme" (Antodaya Anna Yojna, Annapurna Yojna) etc.

\section{PRINCIPLE REASONS FOR EXISTING MALNUTRITION IN INDIA}

The problem of malnutrition can largely be attributed to the lack of improvement in agricultural productivity owing to inadequate resources and markets needed to obtain agricultural stability. An agrarian crisis is currently an area of worry in India and it has a variety of causes, the prominent being the reduction in government's expenditure devoted to development in the nineties, particularly in rural areas. ${ }^{[6]}$ In urban areas, a large proportion of informal workforce along with unplanned growth of slums lacking in the basic health and hygiene facilities is of principle concern. Rapid growth of urban centres has led to substandard housing on marginal land and overcrowding. Proliferation of these urban slums lacking in basic amenities such as proper shelter, safe drinking water and sanitary hygiene has implications for food security since lack of safe drinking water and sanitation leads to poor biological utilization of food and frequent episodes of morbidity. ${ }^{[7]}$ Gender has been found to be an important determinant of malnutrition among young children. Gender inequality places the female child at a disadvantage compared to males and causes them to suffer more. ${ }^{[8,9]}$

\section{WAY FORWARD}

\section{Measures to improve agricultural productivity and food storage}

The government policies should focus essentially on growth in agriculture mainly through rationale distribution of cultivable land, improving the size of the farms and providing security to the tenant cultivators apart from providing the farmers with improved technology for cultivation and improved inputs like irrigation facilities, availability of better quality seeds, fertilizers and credits at lower interest rates. One main reason why food is not distributed equitably is that a significant amount is wasted. In India, about 7\% of grain and 30\% of fruit and vegetables produced annually are wasted due to lack of proper storage systems. ${ }^{[10]}$ It would be useful to adopt strategies for food storage which have been implemented successfully in other countries such as China. ${ }^{[1]}$

\section{Nutrition indicators as monitoring tools}

For any nutrition programme, the first priority would be to delineate factors which are likely to adversely affect the nutritional status of individuals within the population at different levels. It will then be possible to construct a strategy aiming to modify these flagged factors. Further, for determining the effectiveness of the intervention nutritional indicators need to be set up that are consistent with the objectives of the programme. These indicators should be specific and easy to identify and comprehend. The indicators measured should give a more precise and easily comparable data.

\section{Reducing Micronutrient deficiencies through population-based approach}

Given the prevalent and widespread distribution of micronutrient deficiencies, it is important to adopt strategies targeting broad spectrum of population. One population approach is commercial fortification, which involves enriching foods products by adding vitamins and minerals to them. With increasing urbanization, commercially fortified foods are likely to reach increasing number of people at risk of deficiency, at a low cost. More specific routes for the vulnerable could be through government programs such as Integrated Child Development Services (ICDS). To accelerate the uptake of fortification, public-private partnership will help in facilitating policymakers and the commercial producers to develop evidence-based programs and low cost staple foods with essential micronutrients.

\section{Crop diversification, establishing food grain banks and promoting household gardening}

Growing of non-cereal crops such as oilseeds, fruits and vegetables etc need to be encouraged. Other option is to promote fruit, milk and fish production. The creation of decentralised food grain banks in each village or block of the district, from which people may get subsidised food grains against food coupons, will be a good option. One of the ways to ensure direct access to food that can be easily grown and prepared could be the concept of home gardening. One good example of household gardening can be seen in Bangladesh where as part of its global effort to eliminate vitamin A deficiency and nutritional blindness, the NGO Helen Keller International implemented a home gardening and nutrition education project. ${ }^{[12]}$

\section{Effective and regular monitoring of nutritional programmes}

Nutrition based programmes with a potential to bring positive results such as ICDS should be implemented effectively under proper supervision. There should be a shift from an emphasis on measuring inputs and outputs to measuring outcomes. Priority should be assigned to the identification of the desired impact and outcomes of the program and then work 'backwards' to figure out which 
outputs would be appropriate to attain those outcomes, and, in turn, the inputs that are needed to deliver those outputs. There should be a system of quality assurance both internal and external in place.

\section{Accurate targeting of below poverty line (BPL) candidates}

The prime agenda for India's food security should be to ensure availability of food grains to the common people at an affordable price. This can be done by more accurate targeting of the BPL population so that they get food at substantially low price. Besides helping out the BPL population, there should be a provision for subsidy on the sale of food grains to above poverty line (APL) customers too. Also, all restrictions on food grains regarding interState movement, stocking, exports and trade financing should be removed. This will reduce the food prices and increase affordability. The Public Distribution System must be made transparent and reliable.

\section{Introduction of innovative employment schemes}

The government should come up with more holistic schemes like Mahatma Gandhi National Rural Employment Guarantee Act (MGNREGA). ${ }^{[13]}$ Such employment schemes will provide a better platform for people to work and earn. This will help to combat rural poverty and in the long run, will aid in securing adequate livelihood within the households of small-holders and land-less agricultural labourers. Promotion of urban and peri-urban agriculture, especially horticulture, can make a vital contribution to food and nutrition security apart from being a source of sustainable livelihoods.

\section{Eliminating gender bias and ensuring women empowerment}

There is a growing need to bring changes in the statutory laws with the motive to strengthen women's entitlements and attach importance to their claims over natural and physical assets. Programmes like Development of Women and Children in Rural Areas (DWCRA) should be strengthened and promoted. ${ }^{[14]}$ Empowering the women to help them exercise their own choices and respond to increasing opportunities could be made possible through education and vocational training along with strengthening and capacity building of gender sensitive governance and institutions. Media and non-governmental organizations (NGOs) could play a momentous role.

\section{Mass mobilization to reach the unreached}

This can be achieved by involving community volunteers selected in consensus with the local population. The classical case of community health volunteering is seen in Thailand, where one community volunteer is bestowed upon the responsibility for motivating and mobilizing a cluster of 10-20 households towards making use of available basic services in the community. ${ }^{[15]}$ Besides this, the volunteer also motivates the local community to engage in foodbased activities and nutrition-relevant actions which are compatible within the community's context. Such an approach will lead to ensuring adequate community participation and efficient use of services available.

\section{Need for intersectorial coordination and community participation}

Nutrition is not a 'stand alone' subject and a multisectoral approach is therefore needed where professionals from the fields of nutrition, health and medicine, health economics, agriculture, environmental sciences, social sciences etc work in a close milieu with the politicians, bureaucrats, private sector and NGOs to devise effective policies and programmes. Community based nutrition programmes need to be jointly developed and implemented by a team consisting of sub-district and district level officials, community representatives and micro level implementers at the grass roots.

\section{REFERENCES}

1. The state of food insecurity in the world 2006. Eradicating world hungertaking stock ten years after the World Food Summit. FAO corporate documentry repository. p.14.

2. Grebmer KV, Ruel MT, Menon P, Nestorova B, Olofinbiyi T, Fritschel H, Yohannes Y, Oppeln CV, Towey O, Golden K, Thompson J Global Hunger Index- The challenge of hunger: focus on the crisis of child under nutrition. Bonn, Washington D. C., Dublin October 2010. p.17.

3. Grebmer KV, Nestorova B, Quisumbing A, Fertziger R, Fritschel H, Lorch RP, Yohannes Y. Global Hunger Index - The challenge of hunger: Focus on financial crisis and gender inequality. Bonn, Washington D. C., Dublin October 2009. p.13.

4. International Institute for Population Sciences, Macro International. National Family Health Survey (NFHS-3), 1998-99, India. Mumbai: National Fact Sheet.

5. International Institute for Population Sciences, Macro International. National Family Health Survey (NFHS-3), 2005-06, India. Mumbai: National Fact Sheet.

6. Jena A.K. Statistics of poverty, or poverty of statistics: A reference to $55^{\text {th }}$ Round of NSS. p.305. Retrieved from: http://mospi.nic.in/mospi_seminarseries_nov04_5_1_final.pdf, accessed on 21.08.2011.

7. Athreya VB, Rukmani R, Bhavani RV, Anuradha G, Gopinath R, Velan AS. Report on the state of food insecurity in urban India. M S Swaminathan Research Foundation, September 2010. p.34.

8. Pande R.P. Selective gender differences in childhood nutrition and immunization in rural India: the role of siblings. Demography 2003;40: 395-418.

9. Husain Z. Gender disparities in completing school education in India: Analyzing regional variations. p.8-9.

10. Mission 2014: Feeding the World. Retrieved from: http://12.000.scripts. mit.edu/mission2014/solutions/food-storage-system-solar-dryers-metalsilos, accessed on 22.08.2011.

11. Shengbin L. Study on farm grain storage in China. Proceedings of the 9th International Working Conference on Stored Product Protection, 15 to 18 October 2006, Campinas, Sao Paulo, Brazil. p.47-52. 
12. Talukder A, Kiess L, Huq N, de Pee S, Hill ID, Bloem MW. Increasing the production and consumption of vitamin A-rich fruits and vegetables: Lessons learned in taking the Bangladesh homestead gardening programme to a national scale. Food and Nutrition Bulletin 2000;21(2): 165-172.

13. Official website of NREGA; http://nrega.nic.in/netnrega/home.aspx, accessed on 24.08.2011

14. Poverty alleviation in rural India-Strategy and programmes. Retrieved from: http://planningcommission.nic.in/plans/planrel/fiveyr/10th/volume2/ v2_ch3_2.pdf, accessed on 24.08.2011.
15. Kraisid Tontisirin, Lalita Bhattacharjee. Community based approaches to prevent and control malnutrition. Asia Pac J Clin Nutr 2008;17(S1) 106-110.

Competing interests The author declares that he has no competing interests of conflict.

Note: The paper was awarded the third best paper at the 3rd Britannia Nutrition Foundation (BNF) Symposium held on 2nd September, 2011 at New Delhi to commemorate the National Nutrition Week. 